\title{
Investigation of the Dielectric Strengths of Locally Sourced Vegetable Oil as an Alternative to Mineral Based Transformer Oil
}

\author{
Prof. Anthony N. Eze \& Dr. Peter I. Okoye \\ Department of Technology \& Vocational Education \\ NnamdiAzikiwe University, Awka, Anambra State.
}

\begin{abstract}
The main purpose of the study was to investigate the dielectric strengths of locally produced vegetable oils from Nigerian farms to compare the dielectric strength of the vegetable oil with the mineral oil to see if vegetable oil can be used as an alternative for insulating and cooling of transformers. It was an experimental research. The experimental procedures adopted in carrying out the investigation were sample collection, processing of sample and storing and testing for different properties such as pour point, flash point, peroxide value determination (aging), moisture content, and breakdown voltage test were conducted and results obtained. The findings of the study indicated that vegetable oil has the highest dielectric constant when placed on the same temperature with the mineral oil. One of the recommendations was that owners and managers of electrical transformers should see the urgent need of using vegetable oil as alternative to mineral oil.
\end{abstract}

Keywords:- Transformer, Dielectric Strengths, Vegetable Oil, Mineral Based Oil.

\section{INTRODUCTION}

The roles of transformer in electrical network cannot be overemphasized. They constitute major deriving forces in utility companies. Transformers are used in transmitting and distributing electricity generated at power stations. Based on the roles which transformers play in power transmission, their failures adversely affect the owners of the transformer and consumers who must remain in darkness till the transformer is repaid. For transformers to work, they need oil and insulants and coolants. Oil monitors the conditions and operations of the transformer to ensure that it is in a perfect working condition (1).

The application of oil to transformer is important because a transformer heats up when being used as a result of resistive losses in the electrical and magnetic properties. Heat has to be rejected because when it becomes excessive, it can increase the temperature of the transformer which is capable of destroying insulation, resulting in transformer failures.

Whenever transformer is in use, heat is generated. The heat is then transported to the oil (2). As the oil gets heated, it moves to the radiator through convection. The oil which the radiator supplies is relatively cool. This then cools the transformer by way of winding. This explains the dielectric strength of oil in relation to transformer.

Dielectric strength is one of the vital qualities which people need to consider in stating or selecting oils for transformer. When a transformer has high voltage, it requires high quality oil but quality is not a major consideration when a transformer is not highly loaded (2). This finds expression in insulations.

According to research (3), there are basically two types of insulations for transformers. They included solid insulation which can be produced from paper varnish, pressboard epoxy as well as woods. The second type is the liquid insulation. A good example is the oil insulation. This serves two major objectives when a transformer is put into use. Oil insulation serves as coolants. It also serves as a veritable material for insulation.

The focus of this study was to investigate how vegetable oil could be used as an alternative to mineral based transformer oil. Vegetable oil also known as natural ester fluid is produced from farm crops such as soya, palm oil, palm kernel oil, groundnut oil among others (3). These vegetable products are preferred to mineral based oils because the former are available, less costly and can lead to better efficiency in the transformer performance. According to research (4) vegetable oil has no toxic elements. They are smooth vis-a-viz mineral based oil. Vegetable oil does not contain organic elements. Unlike mineral based oil, oxidation produced by vegetable oil thickens and polymerizes but in mineral based oil, the oxidation forms sludge precipitations. This is very dangerous for transformers.

\section{Objectives of the Study}

The objectives of this study include to:

- Study or investigate the dielectric strengths of locally produced vegetable oils from Nigerian farms.

- Compare the dielectric strength of the vegetable oil with the mineral oil (petroleum based fluid) to see if it (vegetable oil) can be used as an alternative for insulating and cooling of transformers.

- Look inwards on these local products and try to put them into more useful purposes thereby enhancing the economic standard of local farmers (local content phenomenon). 
Significance of the Study

The research work will be useful in these aspects:

- To provide data for cheaper and yet very effective insulating oils for our electric power equipment.

- To stimulate interest for further research in this area in our higher institutions and research centres.

- The research will stimulate the government into establishing or making agriculture more attractive to our farmers because of increase in demand of these agricultural products.

- It will be of immense benefit to our local farmers by increasing the monetary value and more demand for these oil extracts.

- It will help to generate employment for our young school leavers.

- It will improve the living standard of farmers.

\section{$>$ Scope of the Study}

The study is limited to insulation capability of the mentioned vegetable oils. They include palm oil, palm kernel and groundnut oil. The product of this study is applicable to any country in the whole world.

\section{MATERIALS AND METHOD}

Here, the experimental procedures adopted in carrying out the investigation were highlighted as follow:

- Sample collection

- Processing of sample and storing

- Testing for different properties such as pour point, flash point, peroxide value determination (aging), moisture content, and breakdown voltage test were conducted and results obtained.

\section{> Sample Collection}

The oil samples collected for the test include: palm oil, palm kernel oil, groundnut oil and mineral oil as the reference point.

\section{$>$ Processing of Sample and Storage}

The oil samples were pre-conditioned. The sample bottles or jars were thoroughly cleaned before filling them with the locally processed vegetable oils mentioned above. Thereafter, the oils were heated in oven so as to reduce the moisture content before carrying out the peroxide value determination or aging test as well as other relevant examinations.

\section{Tests Performed/conducted in the Study}

Aging or Peroxide Determination- This was performed in order to find out the effect of aging on these oils.

- Pour point and Flash point-The pour point test was carried out in order to ascertain the temperature at which these oils will begin to flow or the point at which they will begin to freeze. The flash point is the temperature at which the oil will begin to ignite. The test was useful in determining the thermal conductivity of the oil.
- Moisture Content- The moisture content affects the breakdown voltage of oils. Hence, determining the moisture content will give useful information on how best to treat the oil before using as transformer oil. This test was carried out at PRODA (NASENI) Enugu.

- Breakdown voltage -Breakdown voltage is defined as the value of an applied AC voltage at which disruptive discharge begins. Therefore, the most common requirement that an insulating fluid must meet is the $\mathrm{AC}$ breakdown voltage. A variety of standard test methods are used where a small volume of oil is subjected to an almost homogenous electric field between two electrodes immersed in the insulation fluid. The voltage is increased at a controlled rate until breakdown occurs. The standard international test is that described in IEC 60165 , which uses an electrode separation of $2.5 \mathrm{~mm}$ and a voltage increase rate of $2000 \mathrm{~V} / \mathrm{s}$.

\section{> Measurement Procedures for Breakdown down Voltage Testing \\ First voltage application is started approximately 5 minutes after completion of the filling and there were no air bubbles visible in the electrode gap. The applied voltages were increased progressively from zero until breakdown occurred. The measurements were carried out 6 times at the interval of 2 minutes.}

- Location of test: The experiments were all conducted at TCN, Enugu Transmission Station Equipment while the following equipment were used, namely: (i) Megger calibrated in KV (oil test set) (ii) Model (OTS 60PB) oil tester set (iii) Electrode gap $=2.5 \mathrm{~mm}$ (iv) $\mathrm{BS} 148$ (1984).

- Precaution: Caution was taken by ensuring that oil settled down inside the Megger before testing.

\section{$>$ Findings of the Study}

The major findings of the study are as follows:

- Vegetable oils contains 0.93 density while mineral oil contains 0.88

- The pour point of vegetable oil is -20 while the pour point of mineral oil is -45

- The flash point of vegetable oil is 330 while that of mineral based oil is 152

- The kinetic viscosity of vegetable oil is 32.9 while that of mineral oil is 8.13

- The total acid value of vegetable oil is 0.035 while that of mineral based oil is $<0.01$

- The moisture content of vegetable oil is 43 while that of mineral oil is $<10$

- The breakdown voltage for the vegetable oil is 77 while that of the mineral oil ranges between 70-75

- The relative permittivity of vegetable oil is 2.91 unlike mineral oil which has 2.2

- The volume resistivity of vegetable oil is $3.7 \times 1012$ while that of mineral oil is $7.6 \times 1015$. 


\section{DISCUSSION}

The findings of the study indicated that vegetable oil has the highest dielectric constant when placed on the same temperature with the mineral oil. This places vegetable oil at a very advantageous position over mineral based oil as it would experience very low electric stress if used to power transformer. It was also found that the dissipation factor of the vegetable oil is not as high as that of mineral oil. This implies that vegetable oil has very low dielectric loss than the mineral based oil. The vegetable oil has very low temperature because of the high water content in it. This is not so with the mineral based oil.

\section{CONCLUSION}

The conclusion in this study is that vegetable oil can serve as an alternative to mineral based transformer oil. Vegetable oil is cheaper and ensures high efficiency in the performance of the transformer when compared with mineral oil.

\section{RECOMMENDATIONS}

The recommendations of the study are as follows:

Owners and managers of electrical transformers should see the urgent need of using vegetable oil as alternative to mineral oil.

Government should encourage farming through incentives in order to guarantee raw materials for producing vegetable oil in a large scale

$>$ Local industries that produce vegetable oil should be encouraged by the government through low taxation to avoid extinction in the global market. The government's support to the industries will place them on comparative advantages with foreign industries.

\section{REFERENCES}

[1]. J. Maulbetch, "Magnetic Fluids Could Cut Transformer Upgrade Costs" EPRI Journal 1997, pp 68-72.

[2]. D.C Abeysundara, C. Weerakoon, Lucas, J.R., Gunatunga, K.A.I., and Obadage, K.C. "Coconut Oil as an Alternative to Transformer Oil", ERU, Symposium Sri Lanka, 2001, pp 1-11.

[3]. Cigre working group A2.35: "Technical brochure 436Experiences in service with new insulating liquids"

[4]. L. A. T. Honary, Biodegradable/Biobased Lubricants and Greases, Machinery Lubrication Magazine Issue No. 200109, Noria Corporation, (2004) www.oilmaintenance.com.

[5]. A. C. Wilson, "Insulating Liquids: Their Uses, Manufacture and Properties", London, U.K., Institution of Electrical Engineers, 1980.

[6]. T.V. Oommen, "Vegetable Oils for Liquid-filled Transformers", IEEE Electrical Insulation Magazine, Nol8, Vol.1, pp 7-11,2002.

[7]. P Macshane, et al: "Natural ester dielectric fluid development", 2005 IEEE/PES transmission and distribution conference, Dallas, 2006.

[8]. S Tenbohlen, et al: "Application of vegetable oilbased insulating fluids to hermetically sealed power transformers" Cigre Paris session, 2008. [7]

[9]. 1EC: IEC 60156 Ed. 2.0b: "Insulating liquids Determination of the breakdown voltage at power frequency - Test method", 1995.

[10]. Standard Specification for Natural (Vegetable Oil) Ester Fluids Used in Electrical Apparatus, ASTM D6871-03, ASTM International, West Conshohocken, PA USA.

\section{APPENDICES}

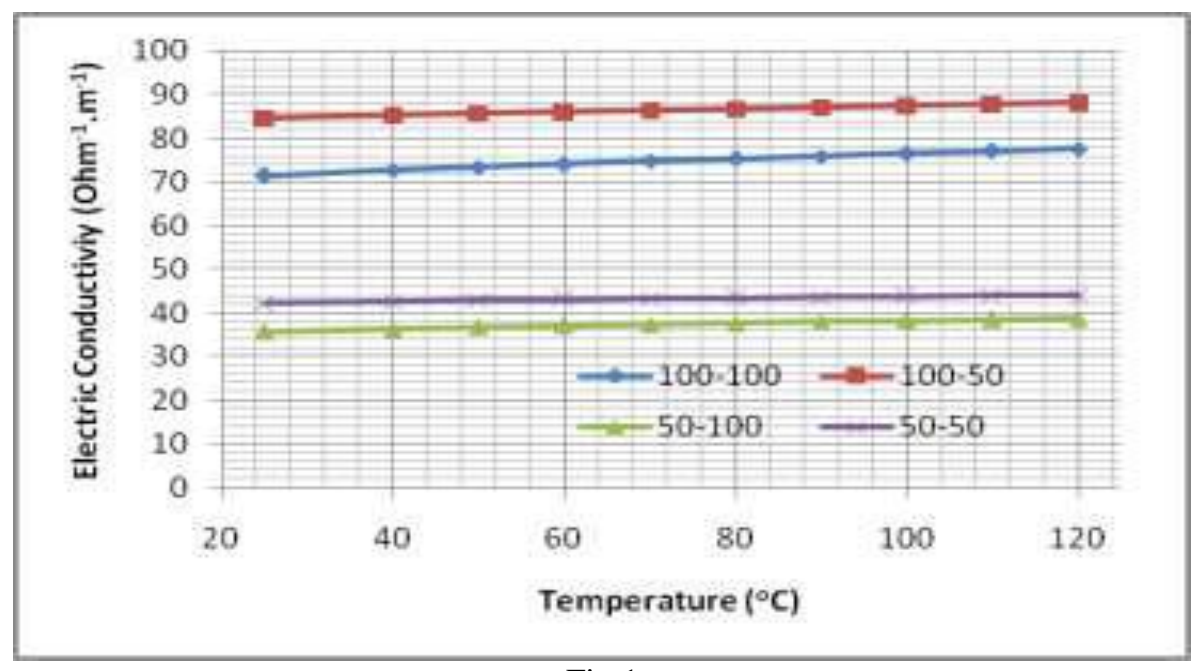

Fig 1 


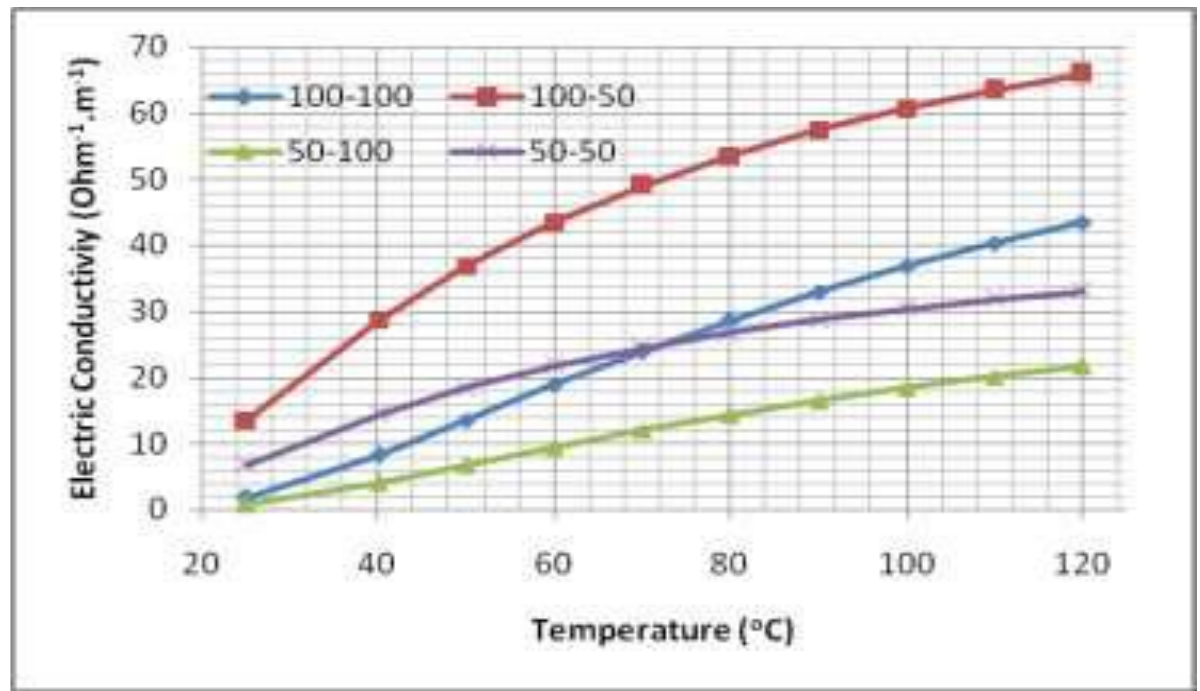

Fig 2 